\title{
Pilot-scale experimental studies on ethanol purification by cyclic stripping
}

DOI:

10.1002/aic.16673

\section{Document Version}

Accepted author manuscript

Link to publication record in Manchester Research Explorer

\section{Citation for published version (APA):}

Maleta, V. N., Bedryk, O., Shevchenko, A., \& Kiss, A. (2019). Pilot-scale experimental studies on ethanol purification by cyclic stripping. American Institution of Chemical Engineers Journal. https://doi.org/10.1002/aic.16673

\section{Published in:}

American Institution of Chemical Engineers Journal

\section{Citing this paper}

Please note that where the full-text provided on Manchester Research Explorer is the Author Accepted Manuscript or Proof version this may differ from the final Published version. If citing, it is advised that you check and use the publisher's definitive version.

\section{General rights}

Copyright and moral rights for the publications made accessible in the Research Explorer are retained by the authors and/or other copyright owners and it is a condition of accessing publications that users recognise and abide by the legal requirements associated with these rights.

\section{Takedown policy}

If you believe that this document breaches copyright please refer to the University of Manchester's Takedown Procedures [http://man.ac.uk/04Y6Bo] or contact uml.scholarlycommunications@manchester.ac.uk providing relevant details, so we can investigate your claim.

\section{OPEN ACCESS}




\section{$1 \quad$ Pilot-scale experimental studies on ethanol purification by cyclic stripping}

2 Vladimir N. Maleta, ${ }^{1}$ Olesja Bedryk, ${ }^{2}$ Alexander Shevchenko, ${ }^{2}$ Anton A. Kiss ${ }^{3,4 *}$

$3 \quad{ }^{1}$ Maleta Cyclic Distillation LLC Ö̈, Parnu mnt 130-38, 11317 Tallinn, Estonia

$4 \quad{ }^{2}$ National University of Food Technologies, Vladimirskaya st. 68, Kyiv-33, 01601, Ukraine

$5 \quad{ }^{3}$ School of Chemical Engineering and Analytical Science, The University of Manchester, Sackville Street,

6 Manchester, M13 9PL, United Kingdom. E-mail: tony.kiss@manchester.ac.uk,TonyKiss@gmail.com

$7 \quad{ }^{4}$ Sustainable Process Technology Group, Faculty of Science and Technology, University of Twente, PO Box

8217,7500 AE, Enschede, The Netherlands

9

10 Abstract

11 Cyclic distillation is a proven process intensification method for enhanced separation of various mixtures. It uses an alternative operating mode based on separate phase movement which leads to important practical advantages (vs conventional mode) such as: increased column throughput, lower equipment cost (using much less trays at the same reflux ratio) and reduced energy requirements by $20-35 \%$ (smaller reflux ratio at the same number of stages), and better separation performance (up to three times). However, if the impurities to be separated are in very low amounts in the feed then distillation is not favorable from an energy use viewpoint. This article is the first to report the practical performance of a continuous process for ethanol purification by air stripping using a cyclic mode of operation, a novel process that avoids the costs of distillation. The purification of ethanol food grade $(96.4 \%$ vol.) from volatile impurities ( $0.5 \%$ vol.) such as esters, aldehydes and alcohols, is carried out in a hydro-selective column with 5 stages. The lightweight impurities are removed from a stream that is the head fraction of a distillation column. This is usually a waste stream amounting to $3-6 \%$ of the plant production rate. By concentrating the stream with impurities, more ethanol is produced such that the losses are reduced to only $1-1.5 \%$ of the plant capacity. Based on the experimental results presented in this work, a process consisting of two air stripping columns using cyclic operation is proposed for industrial implementation.

Keywords: cyclic stripping, process intensification, mass transfer, efficiency, energy savings

\section{Introduction}

During the past few decades, many advanced distillation technologies have been implemented at industrial scale with the aim to reduce the capital and operating costs, as for example: dividing-wall column, heat-integrated 
1 distillation column, reactive distillation, and cyclic distillation. ${ }^{1}$ Among them, cyclic distillation is a particular process intensification technique that uses a cyclic mode of operation with separate phase movement. The cyclic operation has several key advantages over the conventional operating mode: high tray efficiencies (140-300\% Murphree efficiency), higher throughput (no flooding) and equipment productivity, reduced energy requirements, lower operating costs, and increased quality of products. Several papers and reviews on cyclic distillation are available in literature, covering its history, working principles, modeling and simulation, ${ }^{2}$ simultaneous vs consecutive cycling operation mode, ${ }^{3}$ perfect displacement model and working lines, ${ }^{4}$ mathematical modeling, ${ }^{5}$ driving force based design, ${ }^{6}$ design and control columns, ${ }^{7,8}$ impact of operating parameters on the performance, ${ }^{9}$ new tray designs, ${ }^{10,11}$ pilot-scale studies, $^{12}$ industrial equipment and applications, ${ }^{13}$ and revamping of conventional columns. ${ }^{14}$ It must be noted that cyclic distillation is a continuous process, unlike cyclic rectification and stripping operations employed in batch distillation. ${ }^{15}$

The industrial application of cyclic distillation to the production of ethanol food grade has been also reported in the literature, for the separation and concentration of ethanol from water. ${ }^{4,12}$ Compared to conventional distillation, the number of trays required in case of cyclic distillation is half or less at the same reflux ratio, or the reflux ratio is much smaller at the same number of stages considered. ${ }^{7}$ Based on the previous success stories, one may also consider using cyclic separation to solve other industrial problems related to the production of ethanol. ${ }^{16}$ When the feed stream contains small amount of impurities, gas stripping is a more effective solution than distillation.

The separation by stripping refers to a physical-chemical method of purification, based on the removal of organic and inorganic compounds from a liquid by using an inert gas or air. The degree of removal of light components from the liquid depends on their chemical nature and increases with increasing the temperature of the solution and the contact surface area. When the air bubbles through aqueous solutions, the vapor of the dissolved component diffuses into air bubbles and is carried out by them onto the liquid surface. The desorbed substances (carried out by the gas) are usually directed to incineration. The equilibrium partial pressure of the removed substance is determined by Henry's law. The amount of substance transferred from the liquid phase to the gas phase is proportional with the mass transfer coefficient (in the gas phase), the G-L contact surface area, and the average driving force. The stripping process can be carried out in tray, packed and spray columns. It is the most intense in 'foaming mode' for tray columns, and in 'emulsification mode' for packed columns. In the production of ethanol food grade, it is necessary to remove several types of impurities, usually by using three distillation columns. The flowsheet of a typical ethanol production plant is shown in Figure 1 and consists 
of a beer column pre-concentrating ethanol (C1), hydro-selection column (C2) and a rectification column (C3), a column for end-cleaning which produces high purity ethanol (C4), a column for concentrating impurities (C5), a fusel column (C6), and a methanol column (C7). The light (head), intermediate, and heavy (end) impurities are removed by distillation columns $\mathrm{C} 2, \mathrm{C} 5$, and $\mathrm{C} 7$. It should be noted that the main goals in the purification of ethanol are to obtain a product with a minimum content of impurities and to maximize the yield of products. In addition, energy savings can be achieved further by operating the columns at different pressures, as for example the vapor from the beer column is used to heat up the hydro-selection and the methanol columns.

This work focuses on the purification of ethanol food grade $(96.4 \%$ vol.) from volatile impurities (about $0.5 \%$ vol.) such as esters, aldehydes and alcohols, by a new process based on cyclic stripping carried out in a hydroselective column - in which water is added on the upper tray to increase the volatility of impurities. The lightweight impurities are obtained by distillation as main / head fraction, which is a waste stream with a flowrate in the range of $3-6 \%$ of the productivity of the plant. ${ }^{17}$ The main idea is to install an additional column to recover more ethanol while concentrating the impurities and reducing the waste stream (head fraction) flowrate to only $1-1.5 \%$ of the plant capacity. Purification by distillation is also possible, but it is associated with high energy costs and thus it is not economically appealing. As the concentrate consists of a large part of ethanol, it would be more effective to develop an inexpensive technology based on stripping with air, which allows the recovery of ethanol (and increase the ethanol output without reducing its quality) as well as the removal of volatile impurities (in the outlet air stream) that can be eventually incinerated.

\section{Problem statement}

In the production of food grade ethanol and bioethanol by fermentation, a significant amount of impurities is formed such as ethers, aldehydes and alcohols. During the separation and purification steps, these impurities are concentrated by distillation and removed from the process (in an amount of about $5 \%$ by volume). To increase the yield of ethanol, the stream with impurities is subjected to further concentration of impurities in order to reduce the waste stream - see column C5 in Figure 1 which depicts the flowsheet of the ethanol production plant. Due to the higher concentration of impurities, this product stream is usually disposed by incineration, although it still contains up to $70 \%$ ethanol (so there is an economic loss along with more $\mathrm{CO}_{2}$ emissions). A better and more sustainable option is to recover most of the ethanol and thus further increase the production of the plant (while reducing waste). However, concentrating the head fraction stream by distillation is actually not economically profitable due to high energy expenditure. As shown in a previous study, the internal efficiency of 


\section{$9 \quad$ Materials \& methods}

\section{Experimental setup}

distillation processes drops significantly at either very low concentration (e.g. diluted aqueous feed) of very high concentration of the feed (e.g. only minor amounts of impurities present in the feed) ${ }^{18}$

In this work we propose to solve this problem by cyclic stripping with air (this separation step being added after the existing column C5), which avoids expensive phase change by evaporation. This novel process allows the concentration of ethanol in the liquid phase and at the same time the removal of impurities in the gas outlet (taken out with air) that is eventually burned in a furnace. The experimental results described hereafter provide practical insights into the effectiveness of this new process.

This section describes the materials and methods used in the pilot-scale experimental study of ethanol purification by air stripping in a pilot-scale column operated in cyclic mode.

The pilot-scale experimental setup consists of a transparent column with an internal diameter of $145 \mathrm{~mm}$ and height of $1.5 \mathrm{~m}$, made of organic glass ( $5 \mathrm{~mm}$ thickness) and equipped with 5 Maleta trays; ${ }^{11}$ an air blower (Electric Whirl Air Pump Emmecom SC401MG, electric power $0.85 \mathrm{~kW}$, max. air flowrate $140 \mathrm{~m}^{3} / \mathrm{h}$ ) equipped with a frequency converter (to change the air flowrate); a water pump (Grundfos UPS $25-40180$ 1x220); two electric solenoid valves (ODE 21W4ZB250); a water rotameter flow meter (LZS-32 1"), a pressure sensor (Aplisens PC-28); a Hot Wire Anemometer for measuring temperature, volume flow and flow velocity (PCE423); two plastic tanks (capacity 40 liters) for feed and bottoms liquids. Figure 2 shows the schematics of the pilot-scale air stripping column operated in cyclic mode.

The experimental setup works as follows. A feed tank (40 liters) is filled with the mixture of water and ethanol of a specific concentration (i.e. the concentrated head fraction). The bottoms liquid tank starts empty. The feed is pumped to the top of the column setup (i.e. to the separator of the exhaust air, and then through the hydraulic seal to the stripping column). The flowrate of liquid is adjusted using a rotameter and a vent (V3). The air stream is fed to the bottom of the column by means of a blower. The air flowrate is regulated by a frequency converter, and measured by an air velocity sensor. The cycle time is set to 20-30 seconds according to the set program by electromagnetic valves. During operation, the liquid flows through the column from the top to the bottom. For this pilot installation, the liquid flow to the column was in the range of 50-300 liters per hour, and the air velocity in the column varies from 0.5 to $1.5 \mathrm{~m} / \mathrm{s}$ (equivalent air flowrate $30-90 \mathrm{~m}^{3} / \mathrm{h}$ ). 


\section{Experimental procedure}

3 The experimental setup was used for stripping impurities (volatile organic substances) and concentrating ethanol in the head fraction stream. The concentration of ethanol in the head fraction is in the range of 7-12\% vol. (for the reason of having similar concentration in beer and in this unit, for further processing as beer). The remaining technological parameters of the air stripping setup are: temperature of the liquid and gas $\left(20{ }^{\circ} \mathrm{C}\right)$, the air flowrate (air velocity in the column was fixed to a value of $1 \mathrm{~m} / \mathrm{s}$ ), and the liquid flowrate (an initial load of 100 liters per hour was chosen). The cycle time was chosen to be optimal for each fluid load, taking into account the time of draining liquid from a tray to the tray below (about 2 seconds). A series of experiments was performed using a constant flowrate of air $\left(80 \mathrm{~kg}\right.$ per hour, at about $\left.20^{\circ} \mathrm{C}\right)$, and a liquid flowrate of 100,75 , and 50 liters per hour, respectively. Thus different ratios of liquid to air flowrates have been used. In order to guarantee the reproducibility of the results, and to determine the limits of using cyclic stripping technology, the separation of the initial mixture was carried out three times. After the first experimental test, the bottom liquid of the previous experiment was used as feed to the stripping column for each following stripping experiment. The quantitative composition of the components in an aqueous ethanol solution was determined by chromatographic analysis.

\section{Results and discussion}

All the components in the mixture are soluble in water hence the liquid phase is a homogeneous mixture. The task of separation is practically reduced to the purification of ethanol from the accompanying light impurities. Due to the low concentration of each component, Henry's law can be followed for each of the components of the mixture separately. All impurities can be arranged in the following categories (based on the activity coefficient effects on the phase equilibria, e.g. volatility change due to activity coefficient at low concentration in water): aldehydes, ethers, methanol, and fusel oils. The experimental results at various operating conditions are given in Table 1, Table 2, and Table 3, while Figure 3 illustrates the reduction of light impurities after each air stripping step (n.b. lines shown as visual aid only). However, the concentration of some components do not have strictly declining trend, due to ethanol losses and also due to an increase of their concentration (as the components heavier than ethanol can not be removed). Thus, it is clear that only two steps are practically sufficient for the effective removal of such impurities. As can be observed from these results, the removal of high volatile esters and aldehydes (n.b. which give 
1 stripping column, their amount practically reduces to zero hence the third treatment is not actually necessary.

2 Methanol is also removed from the mixture, but a minimum concentration threshold of $0.2 \%$ vol is established,

3 after which it is no longer possible to remove methanol by stripping. Taking into account that the initial concentration of methanol in the feed solution can significantly exceed $0.2 \%$ vol, then methanol is partly

5 removed by stripping while the residual amount of methanol is recycled in the process. Alternatively, cyclic distillation (instead of air stripping) can be used to remove methanol completely from the food grade ethanol. The fusel oils fraction can be divided into two types: volatile (n-butanol and n-pentanol) and non-volatile components (isoamyl, isobutyl, isopropyl alcohols and n-propanol). Already after the first treatment, the concentration of volatiles in the top of the column is zero. The low volatile components are recycled in the process, and eventually removed (in column C6 - fusel column). It should also be noted the loss of ethanol in the air stream, which is in the range of max. $10-15 \%$ of the initial amount of alcohol present in the feed stream. The pilot scale experimental results show that the prospects of industrial implementation are favorable. The preliminary calculations for a plant producing ethanol (capacity of 30,000 liters per day, or $10,000 \mathrm{~m}^{3}$ per year) indicate that the installation consists of a series of two connected stripping columns (with a diameter of $300 \mathrm{~mm}$ and height of 2 meters, made of stainless steel, and using 5 Maleta trays each) - see Figure 4 for details. The two cyclic stripping columns are not replacing any of the existing units in Figure 1, but they are actually added after the distillation column C5 in order to further recover ethanol and concentrate the impurities from an otherwise usual 'waste stream'. Remarkably, the cyclic stripping process required low energy usage (e.g. electricity: $3 \mathrm{~kW}$ air pump) and a reasonably small amount of capital investment in the equipment (i.e. 2 column shells, 2 air pumps, automation system, 3 liquid pumps, and optionally 2 tanks).

The total air flowrate to both columns is $350 \mathrm{~m}^{3} / \mathrm{h}$. The exhaust air (that includes the light impurities removed) is sent to a boiler (or an incineration facility). Overall, the quantity of light impurities removed does not exceed $1.5 \%$ of the total amount of air used. Therefore, using the cyclic stripping process in the production of ethanol makes it possible to increase the productivity of the plant by $0.8-0.9 \%$ (of the 30,000 liters per day) leading to an extra production of 80,000 liters ethanol per year, and thus ensuring a short payback time of less than one year. Moreover, the light impurities are removed at reduced $\mathrm{CO}_{2}$ emissions (less waste being burned), thus improving also the overall sustainability of the ethanol production process. 


\section{Conclusions}

The pilot-scale column experiments carried out in this study have shown that air stripping purification of ethanol using a cyclic operation mode is a feasible novel process that is highly effective in recovering ethanol and removing impurities from a waste stream available in industrial processes for ethanol production. The main results and conclusions of this study are the following:

- The high volatile esters (e.g. methyl acetate, isobutyl acetate, ethyl butyrate) and aldehydes (e.g. acetic aldehyde) can be completely removed from the alcohol mixture feed.

- The fusel oils volatile fractions (n-butanol and n-pentanol) are completely removed from the liquid. However, the low-volatile components (isoamyl, isobutyl, isopropyl alcohols and n-propanol) are not removed and the have to be recycled in the process.

- Methanol can be only partly removed from the feed stream, as it reaches a minimum concentration threshold of $0.2 \%$ wt that remains in the liquid.

- The recovery of ethanol from the head fraction (waste amounting 3-6\% of the plant capacity) reduces the waste stream flowrate to only $1-1.5 \%$ of the plant capacity, thus increasing the ethanol output by 80,000 liters ethanol per year (and ensuring a short payback time of less than one year).

\section{Acknowledgment}

AAK gratefully acknowledges the Royal Society Wolfson Research Merit Award. The authors also thank the reviewers for their insightful comments and suggestions.

\section{Literature cited}

1. Kiss AA, Advanced distillation technologies - Design, control and applications, Chichester,UK: JohnWiley \& Sons, Inc., 2013.

2. Bildea CS, Patrut C, Jorgensen SB, Abildskov J, Kiss AA. Cyclic distillation technology - A mini-review. Journal of Chemical Technology and Biotechnology, 2016; 91:1215-1223.

3. Toftegård B, Clausen CH, Jørgensen SB, Abildskov J. New realization of periodic cycled separation. Industrial \& Engineering Chemistry Research. 2016; 55(6):1720-1730.

4. Maleta VN, Kiss AA, Taran VM, Maleta BV. Understanding process intensification in cyclic distillation systems. Chemical Engineering and Processing: Process Intensification. 2011; 50:655-664. 
1 5. Krivosheev VP, Anufriev AV. Mathematical modeling of the cyclic distillation of binary mixtures with a continuous supply of streams to the column, Theoretical Foundations of Chemical Engineering. 2018; 52(3): 307-315.

6. Nielsen RF, Huusom JK, Abildskov J. Driving force based design of cyclic distillation. Industrial \& Engineering Chemistry Research. 2017; 56(38):10833-10844.

7. Patrut C, Bildea CS, Lita I, Kiss AA. Cyclic distillation - Design, control and applications. Separation \& Purification Technology. 2014; 125:326-336.

8. Andersen BA, Nielsen RF, Udugama IA, Papadakis E, Gernaey KV, Huusom JK, Mansouri SS, Abildskov J. Integrated process design and control of cyclic distillation columns. IFAC-PapersOnLine. 2018; 51(18): 542-547.

9. Buetehorn S, Paschold J, Andres T, Shilkin A, Knoesche C. Impact of the duration of the vapor flow period on the performance of a cyclic distillation, Chemie Ingenieur Technik. 2015; 87:1070-1070.

10. Szonyi L, Furzer IA. Periodic cycling of distillation-columns using a new tray design. AIChE Journal. $1985 ; 31: 1707-1713$.

11. Maleta BV, Maleta O. Mass exchange contact device. US Patent 8,158,073, April 17, 2012.

12. Maleta BV, Shevchenko A, Bedryk O, Kiss AA. Pilot-scale studies of process intensification by cyclic distillation. AIChE Journal. 2015; 61:2581-2591.

13. Kiss AA, Maleta VN. Cyclic distillation technology - A new challenger in fluid separations. Chemical Engineering Transactions. 2018; 69:823-828.

14. Kiss AA, Bildea CS. Revive your columns with cyclic distillation, Chemical Engineering Progress. 2015; $111(12): 21-27$.

15. Flodman HR, Timm DC. Batch distillation employing cyclic rectification and stripping operations. ISA Transactions. 2012; 51(3):454-460.

16. Katzen R, Madson PW, Moon GD. Ethanol distillation: The fundamentals, in Lyons TP, Jacques KA, Kelsall DR (Eds), The alcohol textbook: A reference for the beverage, fuel and industrial alcohol industries. 3rd Edition, Nottingham,UK: Nottingham University Press, 1999.

17. Tsygankov PS. Distillation installation in alcohol industry. Moscow:Russia, Light and food industries, 1984.

18. Blahusiak M, Kiss AA, Kersten SRA, Schuur B. Quick assessment of binary distillation efficiency using a heat engine perspective. Energy. 2016; 116:20-31. 


\section{$1 \quad$ Tables}

2 Table 1. Experimental results for cyclic stripping. Parameters: air flowrate $=80 \mathrm{~kg} / \mathrm{h}$, water flowrate $=100 \mathrm{~L} / \mathrm{h}$

3 or $6 \mathrm{~m}^{3} / \mathrm{m}^{2} \mathrm{~h}$, initial ethanol concentration in the feed $=7.1 \%$ vol., ethanol in the bottom $=6.2 \%$ vol.

4

\begin{tabular}{|c|c|c|c|c|c|c|c|}
\hline No. & Component & Group & Unit & Feed 1 & $\begin{array}{l}\text { Bottom } 1 \\
=\text { Feed } 2\end{array}$ & $\begin{array}{l}\text { Bottom } 2 \\
=\text { Feed } 3\end{array}$ & Bottom 3 \\
\hline 1 & Acetic aldehyde & Aldehyde & $\mathrm{mg} / \mathrm{L}$ ethanol & 317 & 105 & 42 & 36 \\
\hline 2 & Methyl acetate & Ester & mg/L ethanol & 116 & 64.5 & 23 & 17 \\
\hline 3 & Methanol & Alcohol & $\%$ vol. & $1.0 \%$ & $0.15 \%$ & $0.13 \%$ & $0.19 \%$ \\
\hline 4 & Isopropanol & Alcohol & mg/L ethanol & 21 & 20.2 & 19 & 20 \\
\hline 5 & Isobutyl acetate & Ether & $\mathrm{mg} / \mathrm{L}$ ethanol & 12.6 & 0 & 0 & 0 \\
\hline 6 & n-Propanol & Alcohol & mg/L ethanol & 52 & 67 & 54 & 73 \\
\hline 7 & Ethyl butyrate & Ester & mg/L ethanol & 194 & 0 & 0 & 0 \\
\hline 8 & Isobutyl alcohol & Alcohol & mg/L ethanol & 667 & 583 & 438 & 574 \\
\hline 9 & n-Butanol & Alcohol & mg/L ethanol & 135 & 0 & 0 & 0 \\
\hline 10 & Isoamyl alcohol & Alcohol & mg/L ethanol & 133 & 89 & 73 & 98 \\
\hline 11 & n-Pentanol & Alcohol & $\mathrm{mg} / \mathrm{L}$ ethanol & 28 & 0 & 0 & 0 \\
\hline
\end{tabular}


1 Table 2. Experimental results for cyclic stripping. Parameters: air flowrate $=80 \mathrm{~kg} / \mathrm{h}$, water flowrate $=75 \mathrm{~L} / \mathrm{h}$ or

$24.5 \mathrm{~m}^{3} / \mathrm{m}^{2} \mathrm{~h}$, initial ethanol concentration in the feed $=7.2 \%$ vol., ethanol in the bottom $=5.9 \%$ vol.

3

\begin{tabular}{|c|c|c|c|c|c|c|c|}
\hline No. & Component & Group & Unit & Feed 1 & $\begin{array}{l}\text { Bottom } 1 \\
=\text { Feed } 2\end{array}$ & $\begin{array}{l}\text { Bottom } 2 \\
=\text { Feed } 3\end{array}$ & Bottom 3 \\
\hline 1 & Acetic aldehyde & Aldehyde & $\mathrm{mg} / \mathrm{L}$ ethanol & 660 & 53 & 8.8 & 8 \\
\hline 2 & Methyl acetate & Ester & $\mathrm{mg} / \mathrm{L}$ ethanol & 265 & 44 & 0 & 0 \\
\hline 3 & Methanol & Alcohol & $\%$ vol. & $1.92 \%$ & $0.19 \%$ & $0.15 \%$ & $0.12 \%$ \\
\hline 4 & Isopropanol & Alcohol & $\mathrm{mg} / \mathrm{L}$ ethanol & 29 & 24 & 23,4 & 17.5 \\
\hline 5 & Isobutyl acetate & Ether & mg/L ethanol & 21 & 0 & 0 & 0 \\
\hline 6 & n-Propanol & Alcohol & $\mathrm{mg} / \mathrm{L}$ ethanol & 121 & 76 & 88 & 76 \\
\hline 7 & Ethyl butyrate & Ester & mg/L ethanol & 373 & 0 & 0 & 0 \\
\hline 8 & Isobutyl alcohol & Alcohol & mg/L ethanol & 1341 & 696 & 518 & 362 \\
\hline 9 & n-Butanol & Alcohol & mg/L ethanol & 208 & 0 & 0 & 0 \\
\hline 10 & Isoamyl alcohol & Alcohol & mg/L ethanol & 241 & 122 & 110 & 72 \\
\hline 11 & n-Pentanol & Alcohol & mg/L ethanol & 35 & 0 & 0 & 0 \\
\hline
\end{tabular}


1 Table 3. Experimental results for cyclic stripping. Parameters: air flowrate $=80 \mathrm{~kg} / \mathrm{h}$, water flowrate $=50 \mathrm{~L} / \mathrm{h}$ or

$23 \mathrm{~m}^{3} / \mathrm{m}^{2} \mathrm{~h}$, initial ethanol concentration in the feed $=7.4 \%$ vol., ethanol in the bottom $=5.8 \%$ vol.

3

\begin{tabular}{|c|c|c|c|c|c|c|c|}
\hline No. & Component & Group & Unit & Feed 1 & $\begin{array}{l}\text { Bottom } 1 \\
=\text { Feed } 2\end{array}$ & $\begin{array}{l}\text { Bottom } 2 \\
=\text { Feed } 3\end{array}$ & Bottom 3 \\
\hline 1 & Acetic aldehyde & Aldehyde & $\mathrm{mg} / \mathrm{L}$ ethanol & 381 & 27 & 8.8 & 8.4 \\
\hline 2 & Methyl acetate & Ester & $\mathrm{mg} / \mathrm{L}$ ethanol & 147 & 15 & 0 & 0 \\
\hline 3 & Methanol & Alcohol & $\%$ vol. & $1.14 \%$ & $0.18 \%$ & $0.2 \%$ & $0.2 \%$ \\
\hline 4 & Isopropanol & Alcohol & $\mathrm{mg} / \mathrm{L}$ ethanol & 18 & 23 & 21.3 & 17.7 \\
\hline 5 & Isobutyl acetate & Ether & mg/L ethanol & 10 & 0 & 0 & 0 \\
\hline 6 & n-Propanol & Alcohol & mg/L ethanol & 58 & 129 & 125 & 115 \\
\hline 7 & Ethyl butyrate & Ester & mg/L ethanol & 218 & 0 & 0 & 0 \\
\hline 8 & Isobutyl alcohol & Alcohol & mg/L ethanol & 821 & 819 & 574 & 463 \\
\hline 9 & n-Butanol & Alcohol & mg/L ethanol & 149 & 0 & 0 & 0 \\
\hline 10 & Isoamyl alcohol & Alcohol & mg/L ethanol & 149 & 168 & 122 & 93 \\
\hline 11 & n-Pentanol & Alcohol & $\mathrm{mg} / \mathrm{L}$ ethanol & 28 & 0 & 0 & 0 \\
\hline
\end{tabular}




\section{$1 \quad$ List of Figure Captions}

2 Figure 1. Flowsheet of an ethanol production plant: $\mathrm{C} 1$ - beer column, $\mathrm{C} 2$ - hydro-selection column, C3 -

3 rectification column, $\mathrm{C} 4$ - column for end-cleaning , C5 - column for concentrating impurities, C6 - fusel column, C7 - methanol column, $\mathrm{P}$ - steam, C - condensate, A - atmosphere, V - vacuum, F - fusel alcohol.

Figure 2. Schematics of the pilot-scale column for cyclic stripping operation: 1 - Liquid feed to the stripping column; 2 - Saturated air outlet; 3 - Air feed to the column; 4 - Liquid outlet from the column; 5 - Air intake

$9 \quad$ Figure 3. Concentration of light impurities after each air stripping step

11 Figure 4. Flowsheet of an air stripping system of two columns operated in cyclic mode: 1 - Air feed to the column; 2 - Liquid feed to the column; 3 - Air outlet to boiler (incinerator); 4 - Ethanol to production 


\section{$1 \quad$ Figures}

2

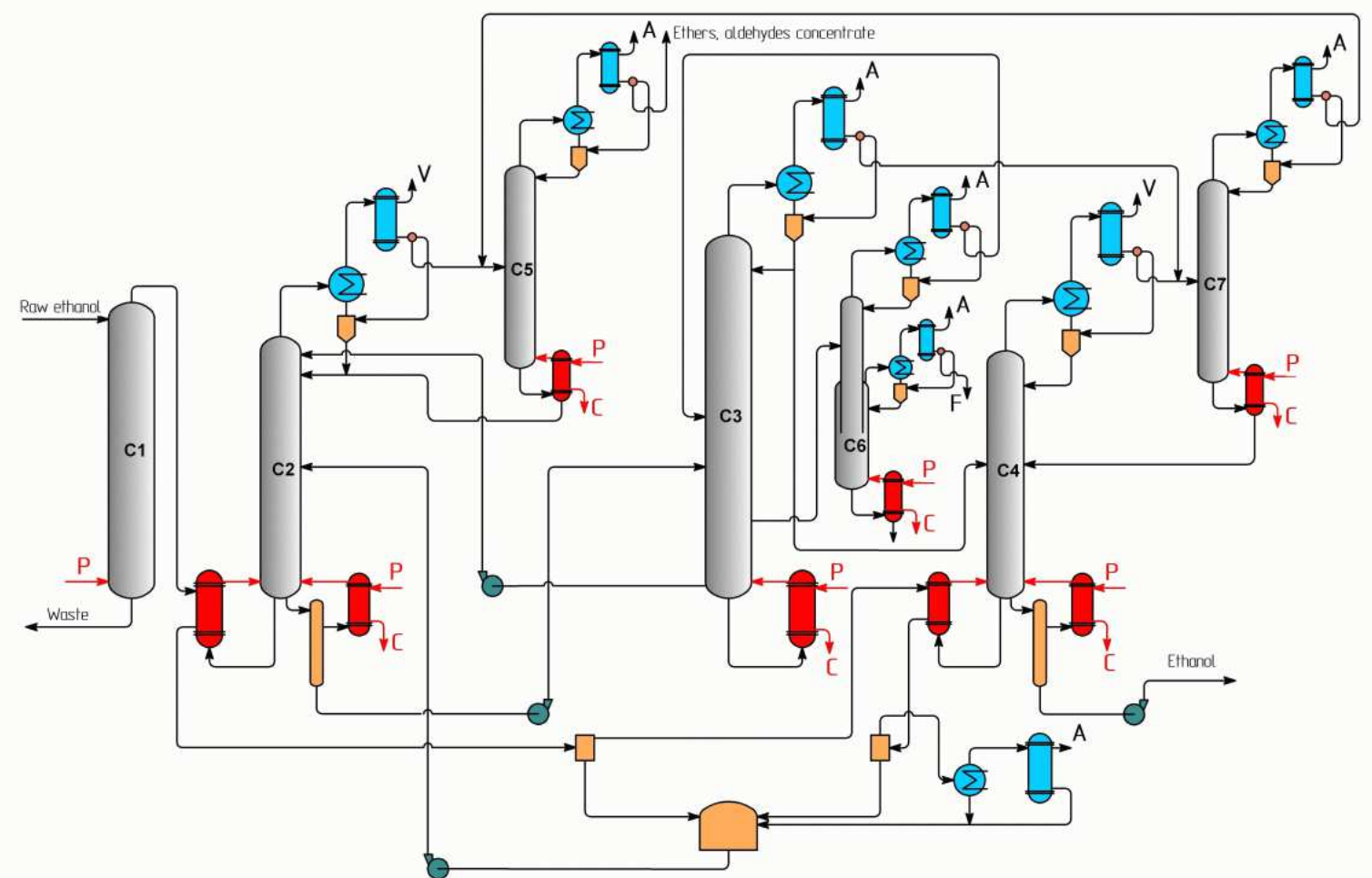

Figure 1. Flowsheet of an ethanol production plant: C1 - beer column, C2 - hydro-selection column, C3 rectification column, C4 - column for end-cleaning , C5 - column for concentrating impurities, C6 - fusel column, C7 - methanol column, $\mathrm{P}$ - steam, C - condensate, A - atmosphere, V - vacuum, F - fusel alcohol. 


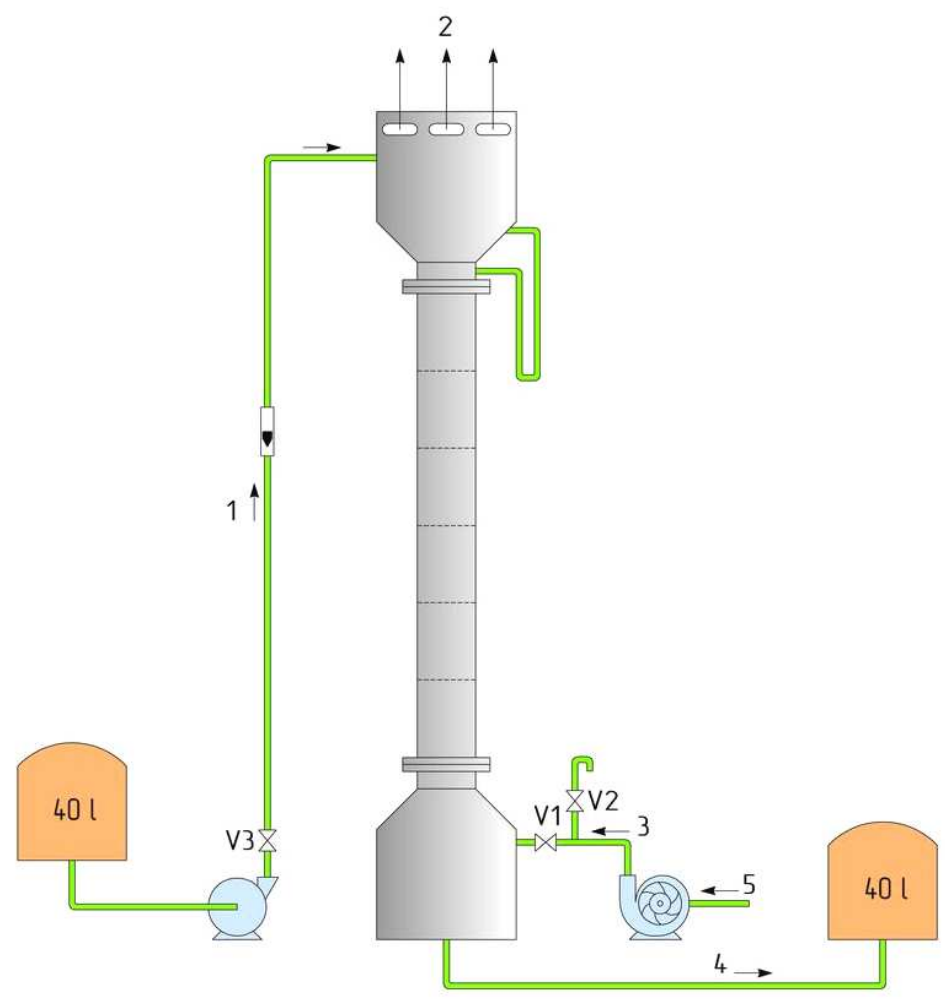

Figure 2. Schematics of the pilot-scale column for cyclic stripping operation: 1 - Liquid feed to the stripping column; 2 - Saturated air outlet; 3 - Air feed to the column; 4 - Liquid outlet from the column; 5 - Air intake 

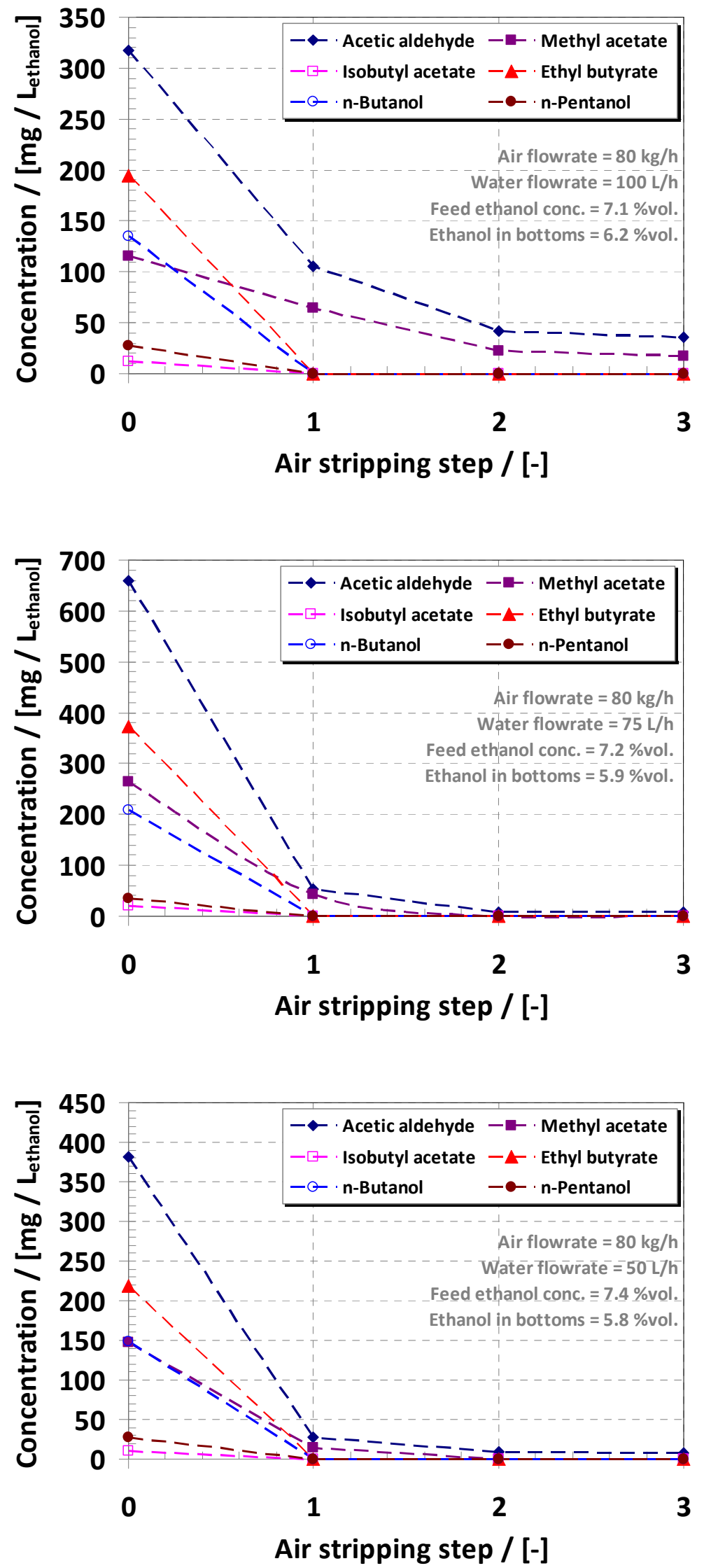

Figure 3. Concentration of light impurities after each air stripping step 


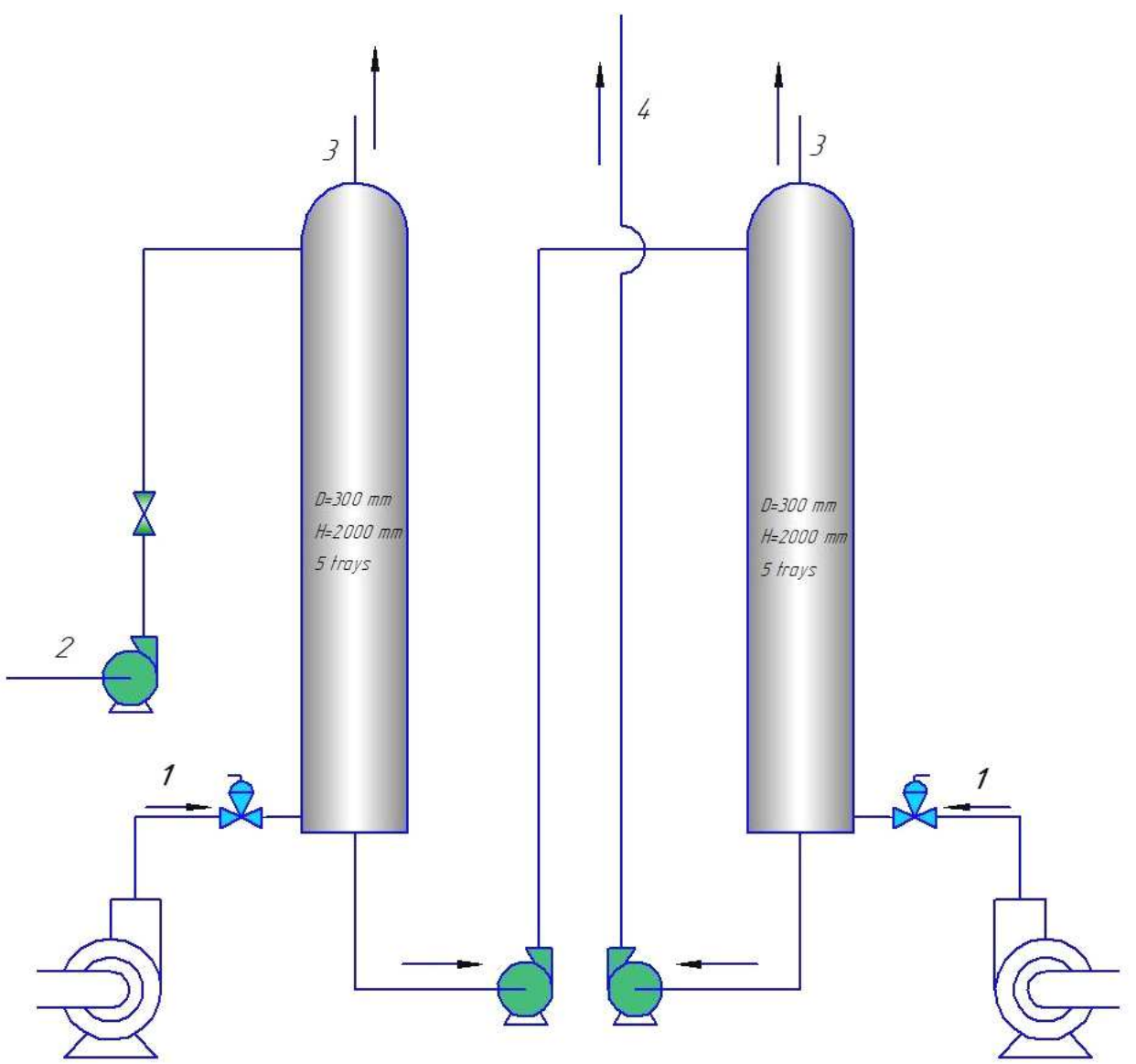

Figure 4. Flowsheet of an air stripping system of two columns operated in cyclic mode: 1 - Air feed to the column; 2 - Liquid feed to the column; 3 - Air outlet to boiler (incinerator); 4 - Ethanol to production 